\title{
Fluid overload in hemodialysis patients: a cross-sectional study to determine its association with cardiac biomarkers and nutritional status
}

\author{
Marlies Antlanger ${ }^{1}$, Manfred Hecking ${ }^{1}$, Michael Haidinger', Johannes Werzowa', Johannes J Kovarik', Gernot Paul ${ }^{2}$,
} Manfred Eigner ${ }^{3}$, Diana Bonderman ${ }^{4}$, Walter $\mathrm{H} \mathrm{Hörl}^{1}$ and Marcus D Säemann ${ }^{1 *}$

\begin{abstract}
Background: Chronic fluid overload is associated with higher mortality in dialysis patients; however, the link with cardiovascular morbidity has not formally been established and may be influenced by subclinical inflammation. We hypothesized that a relationship exists between fluid overload and [i] cardiovascular laboratory parameter as well as between fluid overload and [ii] inflammatory laboratory parameters. In addition, we aimed to confirm whether volume status correlates with nutritional status.

Methods: We recorded baseline characteristics of 244 hemodialysis patients at three hemodialysis facilities in Vienna (Austria) and determined associations with volume measurements using the body composition monitor (Fresenius/Germany). In one facility comprising 126 patients, we further analyzed cardiovascular, inflammatory and nutritional parameters.

Results: We detected predialysis fluid overload (FO) in $39 \%$ of all patients $(n=95)$ with FO defined as $\geq 15 \%$ of extracellular water (ECW). In this subgroup, the absolute FO was $4.4+/-1.5 \mathrm{~L}$ or $22.9 \pm 4.8 \%$ of ECW. A sub-analysis of patients from one center showed that FO was negatively associated with body mass index $(r=-0.371 ; p=\langle 0.001)$, while serum albumin was significantly lower in fluid overloaded patients $(p=0.001)$. FO was positively associated with D-Dimer $(r=0.316 ; p=0.001)$, troponin $T(r=0.325 ; p<0.001)$, and N-terminal pro-B-type natriuretic peptide $(r=0.436$; $p<0.001)$, but not with investigated inflammatory parameters.

Conclusions: Fluid overload in HD patients was found to be lower in patients with high body mass index, indicating that dry weight was inadequately prescribed and/or difficult to achieve in overweight patients. The association with parameters of cardiovascular compromise and/or damage suggests that fluid overload is a biomarker for cardiovascular risk. Future studies should determine if this applies to patients prior to end-stage renal disease.
\end{abstract}

Keywords: Hemodialysis, Fuid overload, Cardiovascular, Inflammation, Bioimpedance

\section{Background}

Patients with end-stage renal disease are exposed to extreme volume shifts and thereby cardiovascular strain as a consequence of interdialytic weight gain, fluid removal during hemodialysis and also chronic fluid overload $[1,2]$. Fluid overload leads to distorted hemodynamic conditions, and most probably higher cardiovascular

\footnotetext{
* Correspondence: marcus.saemann@meduniwien.ac.at

'Department of Internal Medicine III - Clinical Division of Nephrology and Dialysis, Medical University of Vienna, Währinger Gürtel 18-20, 1090, Vienna Austria

Full list of author information is available at the end of the article
}

morbidity [3,4]. Several biomarkers of cardiovascular risk have been studied in hemodialysis patients during the recent years, yet their clinical significance remains vague. Contradicting results regarding pathological cut-off values and prognostic information have been shown [5-8].

To date, only serum N-terminal brain natriuretic peptide (BNP) levels are known to be strongly associated with fluid overload $[3,9,10]$ and have recently even been suggested as a guide for fluid management in hemodialysis patients [11]. Troponin T (TnT) and D-Dimer have been shown to be elevated in the dialysis population in general [12-14], but a direct association with fluid overload has

\section{Biomed Central}


not been demonstrated for TnT [3], or has not yet been studied, as in the case of D-dimer. Thus, further research regarding the association between biomarkers for cardiovascular disease (CVD) and fluid overload is warranted.

Chronic subclinical inflammation may be an additional contributing factor in the intertwined processes of repeated fluid removal and cardiac stress $[15,16]$. It has been suggested that hemodialysis patients are exposed to high endotoxin levels in the blood, possibly due to repeated bacterial translocation from the gut as a consequence of intradialytic changes in blood pressure and/ or tissue perfusion [15]. However, it currently remains speculative whether interdialytic weight gain with high ultrafiltration rates and possibly higher intradialytic blood pressure decline, or chronic fluid overload which is not known to be related to intradialytic hypotension, is more likely to predispose patients to increased inflammation and/or cardiac stress.

Fluid overload has recently been shown to result in adverse outcomes for hemodialysis patients [2,17-19]. For many years, a normohydrated fluid status has been regarded an issue of utmost importance to reduce deranged fluid homeostasis and cardiac morbidity and mortality $[17,18,20,21]$. Adequate fluid status assessment is a critical element in the accurate prescription of hemodialysis and a substantial amount of research - most notably in the field of readily available bioimpedance devices - has taken place within the past couple of years [22-25]. These methods allow for the important differentiation between chronic fluid overload (the amount of residual postdialysis volume overload) $[2,26]$ and interdialytic weight gain (the amount of fluid gained between the end of the dialysis session and the beginning of the next) $[1,19,27]$.

We have recently assessed fluid status in three hemodialysis centers in Vienna, Austria, using the body composition monitor (BCM), a bioimpedance monitoring tool [23]. All three institutions subsequently participated in the 'BVM-Reg' study on dry-weight reduction [28], which investigated whether blood volume monitoring (BVM)-adjusted ultrafiltration rates might reduce intradialytic symptoms associated with a rapid ultrafiltration process in fluid overloaded hemodialysis patients $[29,30]$.

In the present study, we aimed at presenting a crosssectional overview of fluid status in our multicenter patient cohort, hypothesizing that we might be able to confirm the previously shown association between fluid overload and low body mass [2]. Furthermore, we wanted to confirm our hypothesis that fluid overload might be linked with laboratory markers of cardiovascular and/or inflammatory strain.

\section{Methods}

The study was performed in three maintenance hemodialysis centers in Vienna, Austria, comprising
144, 72 and 72 dialysis patients, respectively. The largest center was the maintenance hemodialysis center of the Medical University of Vienna (MUV), while the 2 smaller centers were linked to teaching hospitals of the MUV. As part of the prospective BVM-Reg study which dealt with blood volume monitoring-regulated dry-weight reduction in fluid overloaded hemodialysis patients [28], all our patients routinely underwent BCM measurements. Approval from two independent local Ethics Committees was obtained prior to study initiation (EK\#365/2011 [Medical University of Vienna] and EK11-2221211 [City of Vienna]).

\section{Patient eligibility}

All chronic hemodialysis patients at the participating centers were eligible for the BCM measurement. The department heads of all three dialysis centers previously agreed to establish BCM measurements as part of their routine dialysis practice. Since baseline data were recorded in an anonymous form, written and informed consent was only obligatory for fluid-overloaded hemodialysis patients who subsequently underwent dry weight reduction. Our patients were therefore allowed to decline the BCM measurement, as they can refuse any other routine procedure, but did not have to provide informed consent.

\section{Bioimpedance monitoring}

Patients underwent standardized evaluation of their fluid status with the BCM, a portable bioimpedance monitor (Fresenius Medical Care, Bad Homburg, Germany). All measurements were carried out after the short interdialytic interval. Patients were placed in supine position for about 3-5 minutes before the start of the dialysis session. Electrodes were attached to the hand and foot contralateral to the dialysis fistula or graft, and the measurement was conducted as described in the manufacturer's manual. Clinical data (patient's sex, age, predialytic weight, height, ultrafiltration rate) were documented using a standardized form. All measurements were accomplished within a time frame of \pm 1 week before or after blood collection (center 1 ). Predialysis fluid overload can be described as an absolute value (in liters) or as a relative variable reflected by the expansion of the extracellular water (ECW) which is then calculated as Rel FO $=\mathrm{FO} / \mathrm{ECW} \times 100 \%$. Prior publications have suggested an expansion $\geq 15 \% \mathrm{ECW}$ as defining for Rel FO [2].

\section{Laboratory data}

As part of the quarterly blood sampling policy in the University-associated center, we collected routinely determined baseline laboratory data from 126 patients in that particular center after a long interdialytic interval. We determined blood counts, blood chemistry, coagulation parameters, dialysis quality $(\mathrm{Kt} / \mathrm{V})$, renal osteodystrophia parameters (phosphate, calcium, parathyroid hormone, 
vitamin D levels) and inflammatory and cardiovascular markers (C-reactive protein (CRP), Troponin $\mathrm{T}(\operatorname{Tn} \mathrm{T})$, fibrinogen, D-Dimer and NT-proBNP). C-reactive protein, D-Dimer and serum amyloid A (SAA) were measured with a latex agglutination method (reference values $<1 \mathrm{mg} / \mathrm{dl}$ [CRP], $<0.5 \mu \mathrm{g} / \mathrm{ml}$ [D-Dimer]); (reference range $0-6.4 \mathrm{mg} / \mathrm{l}$ [SAA]). TnT was determined by an enhanced chemiluminescence immunoassay (reference range $0.00-0.03 \mathrm{ng} / \mathrm{ml}$ ), and NT-proBNP was measured with an immunologic test (reference range $0-125 \mathrm{pg} / \mathrm{ml}$ ). All laboratory values were analyzed at the Clinical Institute for Laboratory Medicine at the Medical University of Vienna.

\section{Outliers}

Prior to statistical analyses, patients exceeding percental fluid overload of three standard deviations above or below the mean were excluded ( $\mathrm{n}=1$ patient). Cut-offs for laboratory parameters for which regression analyses were planned, were defined as values exceeding 15 times the upper range of normal. This led to the following exclusions: C-reactive protein (cut-off $>15 \mathrm{mg} / \mathrm{dl}$ ): $\mathrm{n}=2$ patient, D-Dimer (cut-off $>7.5 \mu \mathrm{g} / \mathrm{ml}$ ): $\mathrm{n}=2$ patients, TnT (cut-off $>0.45 \mathrm{ng} / \mathrm{ml}$ ): $\mathrm{n}=4$ patients, and serum amyloid A (cut-off $>96 \mathrm{mg} / \mathrm{l}): \mathrm{n}=11$ patients. As nearly all hemodialysis patients met this criterion regarding NT-proBNP, the definition was abandoned for this parameter. We calculated the median value for NT-proBNP, and compared the resulting groups.

\section{Statistical analysis}

Descriptive statistics were used to report baseline patient characteristics. Results regarding parametric variables are presented as the mean with standard deviation (SD) or median with interquartile ranges (IQR) if values were not normally distributed. Categorical variables are expressed as percentage or ratio.

To assess differences regarding fluid status between the participating centers, one-way ANOVA was used. Subsequently, patients from center 1 were divided into two groups, normohydrated and fluid overloaded patients, with the cut-off set at $\geq 15 \%$ Rel FO. Dehydrated patients with $<-10 \% \mathrm{ECW}$ were thus included into the normohydrated group, as in a prior study [2].

Differences between the fluid overloaded and normohydrated groups were determined by Chi-square test for categorical variables. For numerical variables, MannWhitney-U Test was used for non-normally distributed values (C-reactive protein, $\mathrm{D}$-Dimer, troponin $\mathrm{T}, \mathrm{N}-$ terminal proBNP and serum amyloid A); Student's t-test was applied if values showed Gaussian distribution.

Analyses of association: Spearman's rank correlation coefficient was utilized to measure the dependence between fluid overload and non-normally distributed biomarkers. For the association analysis between fluid overload and body mass index, Pearson's correlation coefficient was applied. Additionally, linear regression modeling was used.

Further, the median was calculated for NT-proBNP and the ensuing two groups (above and below the median) compared with regard to fluid overload.

Results were considered statistically significant at a P-value $<0.05$. The IBM SPSS System for Windows version 19.0.0 (SPSS, Inc., 2010, Chicago, IL) was used for all analyses.

\section{Results}

\section{Fluid status in the participating centers}

288 patients were eligible for bioimpedance measurement, and 252 patients underwent assessment (Figure 1). 36 patients were not measured with the $\mathrm{BCM}$ due to various reasons (hospitalized, out-of-town at the time of the measurement, declined). BCM measurements were incomplete in 8 patients, and are not described. Here we report on 126/144 patients in center 1,63/72 in center 2 and 55/72 in center 3 .

As shown in Table 1, 39\% of all patients met the definition of pre-HD fluid overload ( $\geq 15 \%$ Rel FO). Specifically, $43 \%, 32 \%$ and $36 \%$ of all measured patients in study centers 1,2 , and 3 , respectively, were fluid overloaded. We observed no significant center difference regarding the absolute and relative amount of fluid overload. However, patients from centers 2 and 3 were heavier than patients from center 1 , as reflected by dry weight, body mass index and absolute values for ECW.

As shown in Table 2, absolute values of pre-HD fluid overload in overhydrated patients from center 1 amounted to $4.37 \pm 1.52 \mathrm{~L}$, compared to a pre-HD fluid excess of $1.00 \pm 1.37$ liters in the normohydrated group $(\mathrm{p}<0.001)$.

\section{Association between fluid overload and patient characteristics}

When comparing sex and age between normohydrated and fluid overloaded patients, we observed no significant differences $(\mathrm{p}=0.137$ for sex and $\mathrm{p}=0.110$ for age, Table 2). Furthermore, when comparing short interdialytic intervals, there was no significant difference in the interdialytic weight gain (IDWG) between the fluid overloaded and normohydrated groups, represented by ultrafiltration volume on the day of the $\mathrm{BCM}$ measurement $(1.31 \pm 0.99 \mathrm{~L}$ vs. $1.59 \pm 1.08 \mathrm{~L}, \mathrm{p}=0.144)$.

A negative association was detected for body mass index and fluid overload (Figure 2). A linear regression model showed this direct inverse relationship to be significant $(\mathrm{r}=-0.371 / \mathrm{p}<0.001$, Additional file 1: Figure S1) and the patient group with a BMI $>30 \mathrm{~kg} / \mathrm{m}^{2}$ had highly significant lower relative fluid overload values, while no difference was observed for relative interdialytic weight gain (Figure 2). Serum albumin levels were significantly 


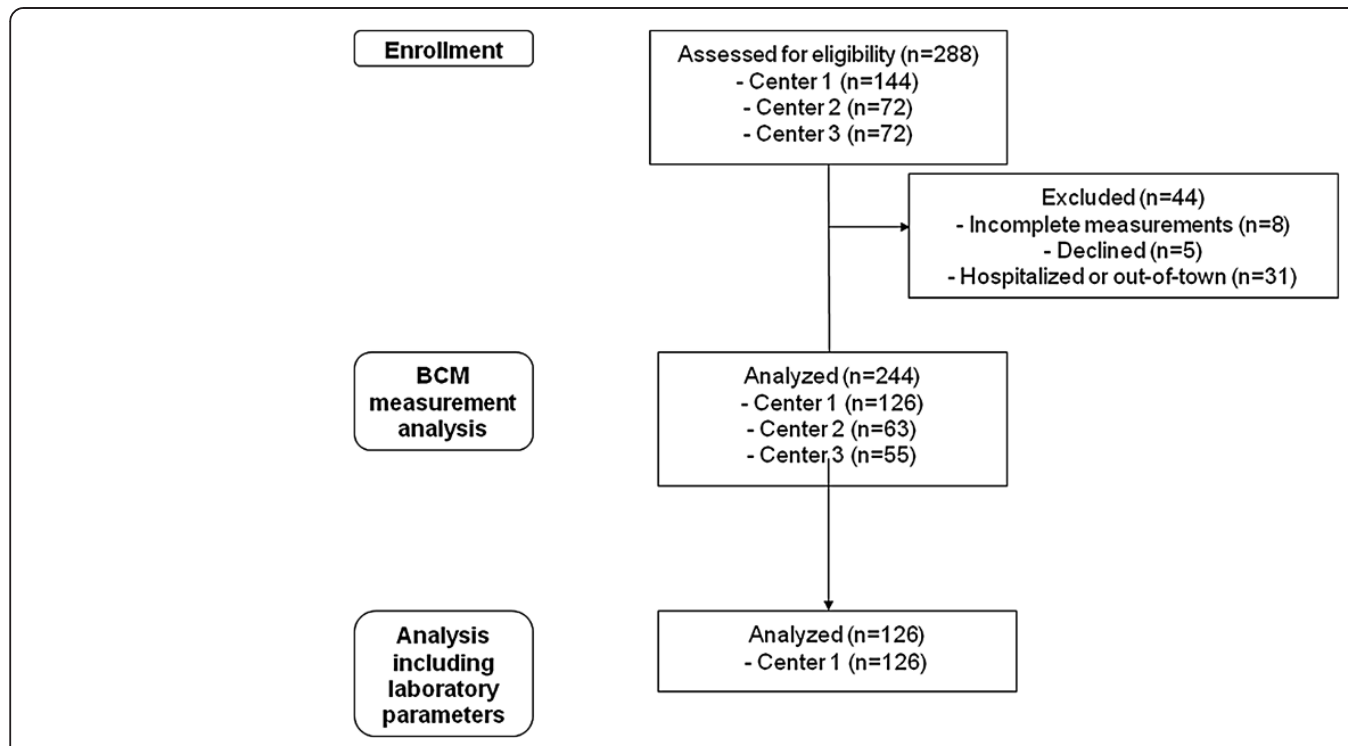

Figure 1 Patient enrollment according to CONSORT flowchart.

lower in the fluid overloaded patient collective. Similarly, patient comorbidities represented by the Charlson comorbidity index (CCI) [31], showed a significant association with fluid overload, as the CCI was significantly lower in patients exhibiting normohydration (mean $4.06 \pm 2.04)$ compared to those with percental fluid overload (mean $4.96 \pm 2.27(\mathrm{p}=0.024)$ ).

Lower body mass index was further associated with higher NT-proBNP levels (Figure 2). A multiple regression analysis was run to predict NT-proBNP from percental fluid overload and comorbidities represented by the Charlson Comorbidity Index. These variables statistically significantly predicted NT-proBNP, $F(2,115)=$ $13.665, \mathrm{p}<0.001, \mathrm{r}=0.438$. Only fluid overload added statistically significantly to the prediction with a $\mathrm{p}<0.001$ ( $\mathrm{p}=0.059$ for CCI).
Association between fluid overload, inflammatory, and cardiovascular biomarkers

Laboratory parameters of inflammation (CRP and SAA) were not significantly elevated in the fluid overloaded patient group (Table 2). Likewise, we did not observe a statistically significant association in correlation analyses between these parameters and fluid overload $(r=0.108 /$ $\mathrm{p}=0.253$ for CRP, $\mathrm{r}=0.124 / \mathrm{p}=0.277$ for serum amyloid $\mathrm{A}$ ). Furthermore, no association was detected between interdialytic weight gain and the mentioned markers (data not shown).

However, parameters of coagulation (D-Dimer), myocardial ischemia and cardiac strain (troponin T and NTproBNP) were significantly higher in the fluid overloaded group (Table 2). Patients below the median NT-proBNP value of $7536 \mathrm{pg} / \mathrm{ml}$ showed significantly lower percental

Table 1 Fluid status assessment in participating centers

\begin{tabular}{|c|c|c|c|c|c|}
\hline Patient characteristic & $\begin{array}{l}\text { All centers } \\
(\mathrm{n}=244)\end{array}$ & $\begin{array}{l}\text { Center } 1 \\
(n=126)\end{array}$ & $\begin{array}{l}\text { Center } 2 \\
(n=63)\end{array}$ & $\begin{array}{l}\text { Center } 3 \\
(n=55)\end{array}$ & P-value \\
\hline Dry weight $[\mathrm{kg}]$ & $75.0 \pm 19.2$ & $72.6 \pm 17.4$ & $77.2 \pm 20.4$ & $80.3 \pm 19.2$ & 0.011 \\
\hline Body mass index $\left[\mathrm{kg} / \mathrm{m}^{2}\right]$ & $25.9 \pm 5.7$ & $25.0 \pm 5.4$ & $26.5 \pm 6.1$ & $27.4 \pm 5.7$ & 0.023 \\
\hline UF [L] & $1.8 \pm 1.3$ & $1.5 \pm 1.0$ & $2.3 \pm 1.4$ & $1.9 \pm 1.3$ & $<0.001$ \\
\hline Fluid overloaded pre-HD & $39 \%$ & $43 \%$ & $32 \%$ & $36 \%$ & 0.282 \\
\hline FO pre-HD [L] & $2.5 \pm 2.2$ & $2.6 \pm 2.3$ & $2.6 \pm 2.3$ & $2.3 \pm 1.8$ & 0.639 \\
\hline FO pre-HD [\% ECW] & $12.6 \pm 10.1$ & $13.1 \pm 10.8$ & $12.7 \pm 9.9$ & $11.6 \pm 8.6$ & 0.556 \\
\hline FO post-HD [\% ECW] & $2.9 \pm 12.3$ & $4.6 \pm 12.4$ & $0.9 \pm 12.7$ & $1.4 \pm 11.5$ & 0.092 \\
\hline ECW pre-HD [L] & $18.7 \pm 4.5$ & $18.2 \pm 4.8$ & $18.6 \pm 4.2$ & $20.1 \pm 3.7$ & 0.046 \\
\hline
\end{tabular}

Abbreviations: UF ultrafiltration, FO fluid overload, ECW extracellular water, $H D$ hemodialysis.

Percentage for categorical data, mean \pm standard deviation for normally distributed numerical variables, median and interquartile ranges for non-normally distributed numerical variables. 
Table 2 Comparison of fluid overloaded and normohydrated patients from center 1

\begin{tabular}{|c|c|c|c|}
\hline Patient characteristic & Fluid overloaded $(n=56)$ & Normohydrated $(n=70)$ & P-value \\
\hline Sex [male] & $68 \%$ & $54 \%$ & 0.137 \\
\hline Age [years] & $61.1 \pm 17.3$ & $56.4 \pm 17.8$ & 0.110 \\
\hline Vascular access [AVF] & $76 \%$ & $87 \%$ & 0.102 \\
\hline BMI $\left[\mathrm{kg} / \mathrm{m}^{2}\right]$ & $23.1 \pm 4.4$ & $26.4 \pm 5.7$ & 0.001 \\
\hline Weight pre-HD [kg] & $69.6 \pm 16.6$ & $75.5 \pm 18.2$ & 0.076 \\
\hline Weight post-HD [kg] & $68.3 \pm 16.5$ & $73.9 \pm 17.9$ & 0.092 \\
\hline UF [L] & $1.3 \pm 1.0$ & $1.6 \pm 1.1$ & 0.144 \\
\hline FO pre-HD [L] & $4.4 \pm 1.5$ & $1.0 \pm 1.4$ & $<0.001$ \\
\hline FO pre-HD [\% ECW] & $22.9 \pm 4.8$ & $5.8 \pm 7.7$ & $<0.001$ \\
\hline FO post-HD [\% ECW] & $14.9 \pm 7.9$ & $-3.0 \pm 9.1$ & $<0.001$ \\
\hline ECW pre-HD [L] & $18.8 \pm 4.0$ & $17.8 \pm 5.3$ & 0.290 \\
\hline No. of antihypertensives & $3.0 \pm 1.7$ & $2.8 \pm 1.7$ & 0.700 \\
\hline Systolic BP pre-HD [mmHg] & $137.7 \pm 23.3$ & $134.6 \pm 18.8$ & 0.413 \\
\hline Diastolic BP pre-HD [mmHg] & $72.9 \pm 15.5$ & $73.5 \pm 14.8$ & 0.829 \\
\hline Protein $[\mathrm{g} / \mathrm{l}]$ & $64.9 \pm 5.2$ & $66.8 \pm 5.3$ & 0.056 \\
\hline Albumin $[\mathrm{g} / \mathrm{l}]$ & $36.4 \pm 3.8$ & $38.5 \pm 2.9$ & 0.001 \\
\hline C-reactive protein $[\mathrm{mg} / \mathrm{dl}]$ & $1.0(0.3-2.3)$ & $0.5(0.2-1.6)$ & 0.129 \\
\hline Hemoglobin [g/dl] & $10.2 \pm 1.1$ & $10.3 \pm 1.2$ & 0.491 \\
\hline Fibrinogen $[\mathrm{mg} / \mathrm{dl}]$ & $389.2 \pm 125.6$ & $418.3 \pm 129.5$ & 0.221 \\
\hline D-Dimer $[\mu \mathrm{g} / \mathrm{ml}]$ & $1.2(0.6-2.1)$ & $0.7(0.3-1.7)$ & 0.021 \\
\hline Troponin T [ng/ml] & $0.07(0.05-0.17)$ & $0.05(0.03-0.08)$ & 0.020 \\
\hline NT-proBNP [pg/ml] & $10436.5(4239.3-35000)$ & $4485.0(1956.7-11979.5)$ & 0.001 \\
\hline Serum amyloid A [mg/l] & $14.5(6.5-34.2)$ & $7.6(5.2-25.1)$ & 0.149 \\
\hline $\mathrm{Kt} / \mathrm{N}$ & $1.5 \pm 0.4$ & $1.5 \pm 0.3$ & 0.596 \\
\hline Charlson comborbidity index & $4.96 \pm 2.27$ & $4.06 \pm 2.04$ & 0.024 \\
\hline
\end{tabular}

Abbreviations: yrs years, AVF arteriovenous fistula, BMI body mass index, HD hemodialysis, UF ultrafiltration, FO fluid overload, ECW extracellular water, No number, $B P$ blood pressure, NT-proBNP N-terminal pro-brain natriuretic peptide, $K t / V$ dialysis adequacy.

Percentage for categorical data, mean \pm standard deviation for normally distributed numerical variables, median and interquartile ranges for non-normally distributed numerical variables.

fluid overload (mean $9.5 \pm 8.7 \%$ ) compared to those above $(17.7 \pm 9.3 \%$; Additional file 2 : Figure S2). We further observed a significant positive association between fluid overload and D-Dimer $(r=0.316 / p=0.001)$, troponin $\mathrm{T}(\mathrm{r}=0.325 / \mathrm{p}<0.001)$ and NT-proBNP $(\mathrm{r}=$ $0.405 / \mathrm{p}<0.001$; Figure 3 ). Of note, blood pressure measurements before hemodialysis and the mean number of antihypertensive drugs per patient were similar between normohydrated and fluid overloaded patients (Table 2).

In a multivariate regression analysis, troponin $\mathrm{T}$ showed to be independently associated with fluid overload (standardized coefficient beta $0.237 / \mathrm{p}=0.007$ ), with a strong confounder found in age (beta $0.372 / \mathrm{p}<0.001$ ), while no influence could be shown for logNT-proBNP (beta $-0.006 / \mathrm{p}=0.958$ ) or NT-proBNP groups below or above $35,000 \mathrm{pg} / \mathrm{ml}$ (beta $0.117 / \mathrm{p}=0.256$ ). Documented coronary artery disease was also not associated with higher troponin $\mathrm{T}$ levels in this model.

\section{Discussion}

In the present analysis, we evaluated volume status in a chronic hemodialysis cohort of 244 patients from 3 hemodialysis centers. First, we observed that a high percentage of patients (39\%) exhibited considerable pre-HD fluid overload. Secondly, we were able to confirm an inverse association between the degree of fluid overload in hemodialysis patients and their body mass index as well as serum albumin. Third, an association was shown for fluid overload and biomarkers of cardiovascular compromise, but not with interdialytic weight gain or blood pressure - which stands in contrast to a study by Passauer et al. where a weak positive correlation between pre- and post-dialytic systolic blood pressures and fluid overload was shown in non-diabetic subjects on hemodialysis [22].

The percentage of patients who met the definition criteria of fluid overload surpassed the previously estimated rate of $20 \%$ in European HD centers [2]. The highest 


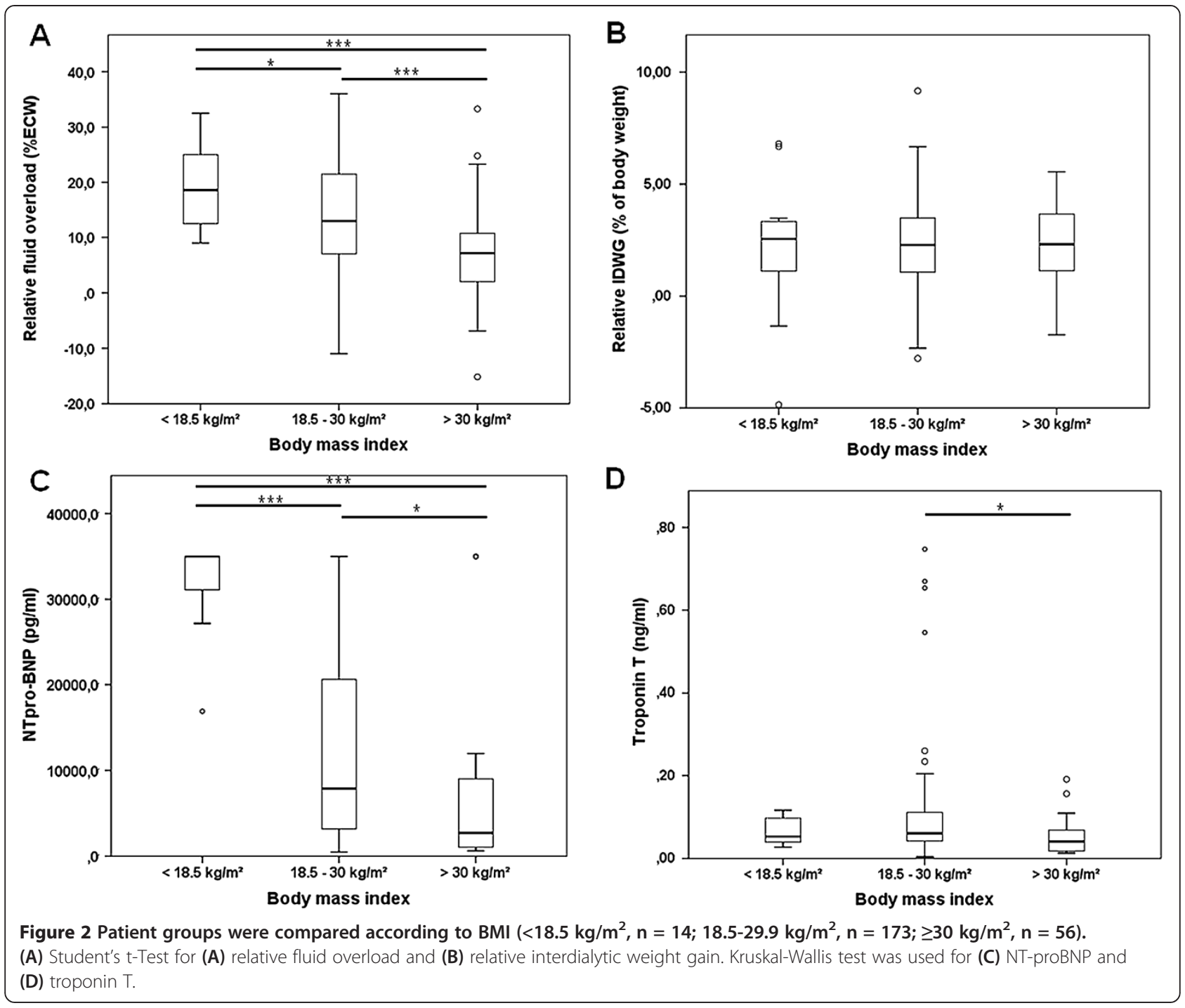

rate of fluid overload was detected in the University-based dialysis unit, possibly because patients from this center comprised a collective with more comorbidities and were therefore more prone to chronic fluid overload. This state of potentially higher morbidity was also associated with significantly lower average body mass in patients dialyzing at the University-based hemodialysis unit.

Lower body mass is known to be strongly associated with increased mortality in the hemodialysis population in general [32] and in fluid overloaded dialysis patients in particular [33]. The same applies for yet another patient cohort: those suffering from congestive heart failure (CHF). For the CHF population, the association between low body mass index and mortality has been shown in the CHARM trial in 2007 as well as other studies analyzing mortality in this population [34,35].

An additional association from our study supporting these findings is the inverse relationship between increasing fluid overload and nutritional status represented by serum albumin and total protein levels. Several factors - patients' comorbid conditions, malnourishment, a certain dilution effect - might be responsible for hypoalbuminemia. This finding has been described previously in a non-dialysis-dependent chronic kidney disease patient group [36] as well as a chronic hemodialysis cohort [2]. In summary, underweight and malnourished, but not necessarily older or more obese patients tend to show higher degrees of fluid overload.

A recent study in 79 dialysis patients aiming at a reduction of blood pressure and antihypertensive medication, yielded interesting results with regard to a lower percentage of body fat in fluid overloaded dialysis patients [37]. These findings are in accordance with our results enforcing the view that underweight patients are more susceptible to fluid overload, whereas adipose patients tend to be in an underhydrated condition. 


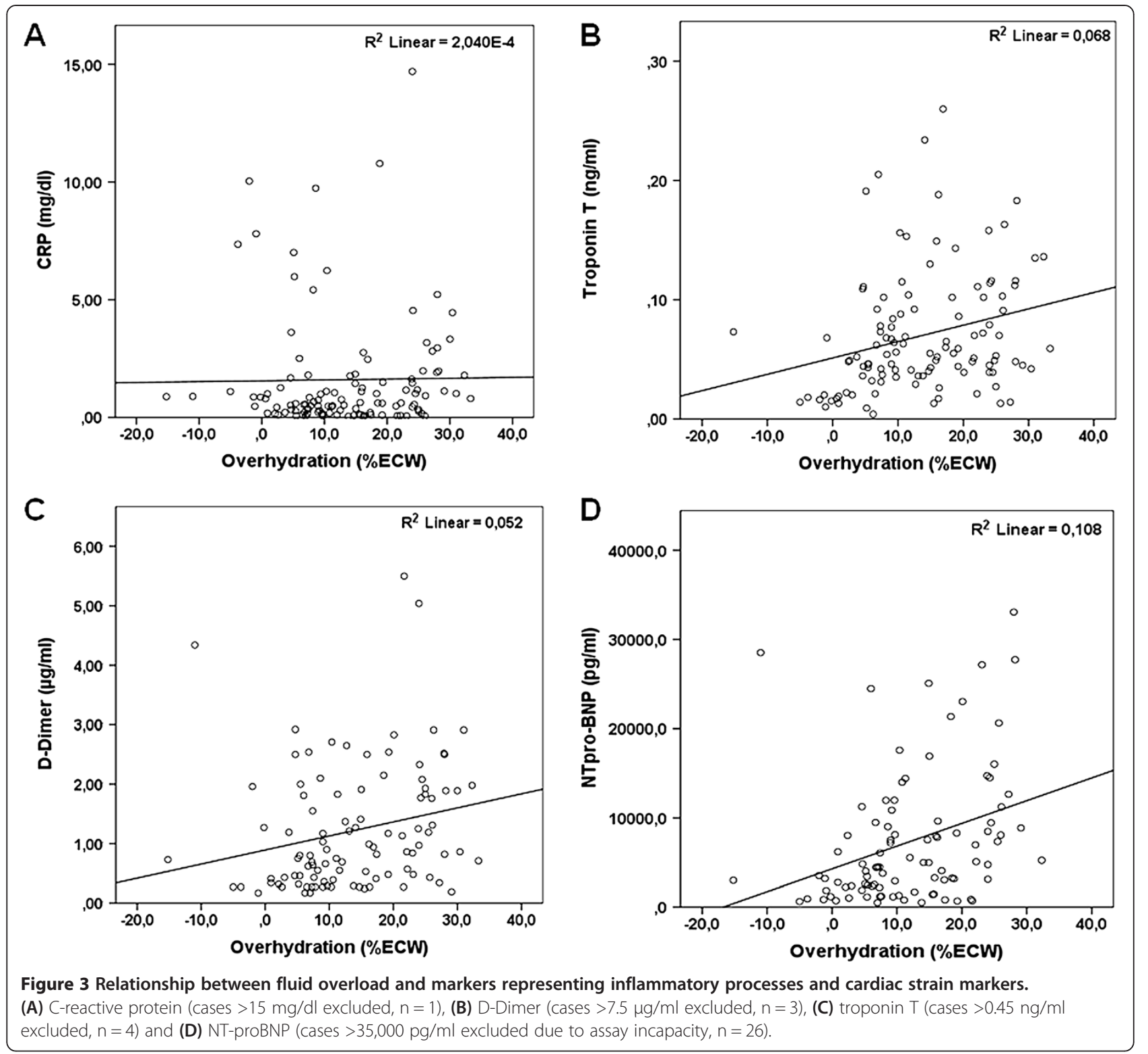

The so-called reverse epidemiology in the hemodialysis population has been a 'hot topic' of the past years and it has been postulated that inverse relationships between mortality and classical cardiovascular risk factors, i.e. body mass index and hypertension, may exist in hemodialysis patients [33,38]. Our results further lend support to this concept, as we could demonstrate that lean patients are generally more fluid overloaded while it is known that fluid overloaded individuals comprise the more morbid patient group with higher markers of the malnutritioninflammation complex syndrome (MICS) [18,39].

This observation might be explained by clinical misclassification - patients appear fluid overloaded due to their physique, when they are in fact normo- or even dehydrated - and/or deliberately insist on dry weight reduction despite normohydration. Clearly, further studies are necessary to delineate the underlying mechanisms of these observations.

The other important finding in our analysis was the statistically significant association of fluid overload and biomarkers representing cardiovascular damage and strain, notably TnT and NT-proBNP. These results correlate well to those by Velasco et al., who used a value similar to fluid overload (time-averaged fluid overload, TAFO) for 30 patients who underwent bioimpedance assessments at three consecutive dialysis sessions. Additionally, these patients underwent cardiac MR imaging in order to quantify left ventricular hypertrophy. The clear association of higher TAFO with higher left ventricular mass index confirms previous assumptions but, 
as is mentioned in their study limitations section, patients might have represented a study population 'above the mean', as they underwent HDF with few hypotensive episodes; additionally, the measured BNP levels were rather low compared to a previous study by Sommerer et al. $[14,40]$. In our multivariate analysis, $\mathrm{TnT}$ proved to be independently associated with fluid overload, but no correlation was observed between TnT and NT-proBNP as well as documented coronary artery disease, which points toward cardiac damage potentially being caused directly by fluid overload and questions the applicability of TnT in the diagnosis of coronary events in hemodialysis patients.

Interestingly, no difference was shown for pre-HD blood pressure measurements between normohydrated and fluid overloaded patients; a fact that could foster a budding theory that the elevation of NT-proBNP and the generation of cardiac insufficiency are rather caused by constant volume overload than hypertension-induced damage in hemodialysis patients. It has previously been shown that, regardless of fluid overload, blood pressure values vary widely. As other factors besides fluid overload, such as sympathetic nervous activity, the renin-angiotensin system, cardiac function and potentially the interdialytic weight gain, also contribute to the genesis of arterial hypertension in hemodialysis patients, it appears challenging to associate the volume status with blood pressure [41,42].

Furthermore, we could show that fluid overload is also associated with increased D-Dimer levels, a parameter representing thrombotic events and a state of coagulatory activation. It is of note that D-Dimer has previously been shown to be particularly elevated in hemodialysis patients with a central venous catheter compared to arteriovenous fistulas [43]; this was confirmed by our analysis (data not shown). As no statistically significant difference was observed regarding dialysis access in normohydrated versus fluid overloaded patients, the observed difference of D-Dimer levels between the two groups might probably be due to another cause, which has yet to be determined.

We acknowledge the following limitations to our analysis: The presented data are descriptive; in the context of the recently performed 'BVM-Reg' study further data will become available and contribute to our current knowledge concerning fluid overload, blood-volume monitoring-guided dry weight reduction and cardiovascular parameters. Further, for many patients psychological issues interrelated with their physique and dry weight might lead to clinical misclassifications regarding their ideal weight as cachectic patients do not wish to further reduce it whereas obese patients might insist on further lowering it. Also, no study-associated cardiac imaging or functional testing was carried out, measures which could potentially be of interest for the exclusion of structural heart disease. It therefore cannot be clearly determined whether NT-proBNP values are solely raised due to fluid overload and renal secretion incapacity or if additional cardiac pathologies, i.e. congestive heart failure, contribute in these patients. NT-proBNP has been described to be of significant value as a marker both of fluid overload [11] as well as of left ventricular dysfunction [4]; both factors seem to show a significant overlap in this special population [44].

\section{Conclusions}

In conclusion, our data show that a significant percentage of middle European maintenance hemodialysis patients are chronically fluid overloaded. Fluid overload is most common in patients with low body mass index and lower serum albumin levels, in accordance with the previously described reverse epidemiology in hemodialysis patients. Additionally, fluid overload is associated with higher levels of biomarkers representing activated coagulation and cardiac muscle decomposition and ischemia, supporting the hypothesis that fluid overload plays a significant role in the generation and augmentation of vascular and cardiac damage. Fluid overload has emerged as a parameter that strongly correlates with cardiovascular biomarkers but seems to be independent of inflammation as well as elevated blood pressure in hemodialysis patients. Therefore, we propose that fluid overload could be defined as an independent single entity - equivalent to a biomarker - with the potential to be introduced for intervention guidance.

\section{Additional files}

Additional file 1: Figure S1. Linear regression analysis of body mass index and fluid overload.

Additional file 2: Figure S2. Low versus high NT-proBNP groups were assessed for percental fluid overload. The median for NT-proBNP was calculated and patients below $(n=62)$ and above the median $(n=61)$ were compared with Student's t-Test.

\section{Competing interests}

The authors declare no competing financial interests.

\section{Authors' contributions}

MA and MHe were responsible for the study conception, patient recruitment, analysis and interpretation of data and manuscript drafting and editing. $\mathrm{MHa}$, JW and JK contributed to patient recruitment and manuscript editing. GP and ME carried out patient recruitment, BCM measurements and data acquisition at centers 2 and 3. DB and WH were involved in the process of manuscript drafting, scientific discussion of the manuscript and critical revision. MS was responsible for study design and supervision, manuscript drafting and editing. All authors read and approved the final manuscript.

\section{Acknowledgements}

The authors would like to thank the nursing staff of the hemodialysis units for their support with bioimpedance measurements and data collection.

\section{Author details}

${ }^{1}$ Department of Internal Medicine III - Clinical Division of Nephrology and Dialysis, Medical University of Vienna, Währinger Gürtel 18-20, 1090, Vienna Austria. ${ }^{2}$ Department of Internal Medicine III, Donauspital KH SMZ Ost, 
Vienna Austria. ${ }^{3}$ Department of Internal Medicine I, Sozialmedizinisches Zentrum Süd - Kaiser-Franz-Josef-Spital mit Gottfried von Preyer'schem Kinderspital, Vienna Austria. ${ }^{4}$ Department of Internal Medicine II - Clinical Division of Cardiology, Medical University of Vienna, Vienna Austria.

Received: 23 March 2013 Accepted: 26 November 2013 Published: 2 December 2013

\section{References}

1. Kalantar-Zadeh K, Regidor DL, Kovesdy CP, Van Wyck D, Bunnapradist S, Horwich TB, Fonarow GC: Fluid retention is associated with cardiovascular mortality in patients undergoing long-term hemodialysis. Circulation 2009, 119(5):671-679.

2. Wizemann V, Wabel P, Chamney P, Zaluska W, Moissl U, Rode C, MaleckaMasalska T, Marcelli D: The mortality risk of overhydration in haemodialysis patients. Nephrol Dial Transplant 2009, 24(5):1574-1579

3. Jacobs $L H$, van de Kerkhof JJ, Mingels AM, Passos VL, Kleijnen WW, Mazairac AH, van der Sande FM, Wodzig WK, Konings CJ, Leunissen KM, et al: Inflammation, overhydration and cardiac biomarkers in haemodialysis patients: a longitudinal study. Nephrol Dial Transplant 2010, 25(1):243-248.

4. David S, Kümpers P, Seidler V, Biertz F, Haller H, Fliser D: Diagnostic value of N-terminal pro-B-type natriuretic peptide (NT-proBNP) for left ventricular dysfunction in patients with chronic kidney disease stage 5 on haemodialysis. Nephrol Dial Transplant 2008, 23(4):1370-1377.

5. Chazot C, Vo-Van C, Zaoui E, Vanel T, Hurot JM, Lorriaux C, Mayor B, Deleaval $P$. Jean G: Fluid overload correction and cardiac history influence brain natriuretic peptide evolution in incident haemodialysis patients. Nephrol Dial Transplant 2011, 26(8):2630-2634.

6. Hickman PE, McGill DA, Talaulikar G, Hiremagalur B, Bromley J, Rahman A, Koerbin G, Southcott E, Potter JM: Prognostic efficacy of cardiac biomarkers for mortality in dialysis patients. Intern Med J 2009, 39(12):812-818.

7. McGill D, Talaulikar G, Potter JM, Koerbin G, Hickman PE: Over time, high-sensitivity TnT replaces NT-proBNP as the most powerful predictor of death in patients with dialysis-dependent chronic renal failure. Clin Chim Acta 2010, 411(13-14):936-939.

8. Kirmizis D, Tsiandoulas A, Pangalou M, Koutoupa E, Rozi P, Protopappa M, Barboutis K: Validity of plasma fibrinogen, D-dimer, and the von Willebrand factor as markers of cardiovascular morbidity in patients on chronic hemodialysis. Med Sci Monit 2006, 12(2):CR55-CR62.

9. Papakrivopoulou E, Lillywhite S, Davenport A: Is N-terminal probrain-type natriuretic peptide a clinically useful biomarker of volume overload in peritoneal dialysis patients? Nephrol Dial Transplant 2012, 27(1):396-401.

10. Booth J, Pinney J, Davenport A: N-terminal proBNP-marker of cardiac dysfunction, fluid overload, or malnutrition in hemodialysis patients? Clin J Am Soc Nephrol 2010, 5(6):1036-1040.

11. Westenbrink BD, Hovinga TK, Kloppenburg WD, Veeger NJ, Janssen WM: B-type natriuretic peptide and interdialytic fluid retention are independent and incremental predictors of mortality in hemodialysis patients. Clin Nephrol 2011, 76(5):373-379.

12. Nelson K, Thethi I, Cunanan J, Hoppensteadt D, Bajwa R, Fareed J, Bansal V: Upregulation of surrogate markers of inflammation and thrombogenesis in patients with ESRD: pathophysiologic and therapeutic implications. Clin Appl Thromb Hemost 2011, 17(3):302-304.

13. Jacobs $L H$, van de Kerkhof J, Mingels AM, Kleijnen WW, van der Sande FM, Wodzig WK, Kooman JP, Van Dieijen-Visser MP: Haemodialysis patients longitudinally assessed by highly sensitive cardiac troponin T and commercial cardiac troponin T and cardiac troponin I assays. Ann Clin Biochem 2009, 46(Pt 4):283-290

14. Sommerer C, Beimler J, Schwenger V, Heckele N, Katus HA, Giannitsis E, Zeier M: Cardiac biomarkers and survival in haemodialysis patients. Eur $\mathrm{J}$ Clin Invest 2007, 37(5):350-356.

15. Mclntyre CW, Harrison LE, Eldehni MT, Jefferies HJ, Szeto CC, John SG, Sigrist MK, Burton JO, Hothi D, Korsheed S, et al: Circulating endotoxemia: a novel factor in systemic inflammation and cardiovascular disease in chronic kidney disease. Clin J Am Soc Nephrol 2011, 6(1):133-141.

16. Gonçalves S, Pecoits-Filho R, Perreto S, Barberato SH, Stinghen AE, Lima EG, Fuerbringer R, Sauthier SM, Riella MC: Associations between renal function, volume status and endotoxaemia in chronic kidney disease patients. Nephrol Dial Transplant 2006, 21(10):2788-2794.

17. Agarwal R: Hypervolemia is associated with increased mortality among hemodialysis patients. Hypertension 2010, 56(3):512-517.
18. Paniagua R, Ventura MD, Avila-Díaz M, Hinojosa-Heredia H, Méndez-Durán A, Cueto-Manzano A, Cisneros A, Ramos A, Madonia-Juseino C, Belio-Caro F, et al: NT-proBNP, fluid volume overload and dialysis modality are independent predictors of mortality in ESRD patients. Nephrol Dial Transplant 2010, 25(2):551-557.

19. Hecking M, Karaboyas A, Antlanger M, Saran R, Wizemann V, Chazot C, Rayner H, Hörl WH, Pisoni RL, Robinson BM, et al: Significance of interdialytic weight gain versus chronic volume overload: consensus opinion. Am J Nephrol 2013, 38(1):78-90.

20. Franz M, Pohanka E, Tribl B, Woloszczuk W, Hörl WH: Living on chronic hemodialysis between dryness and fluid overload. Kidney Int Supp/ 1997, 59:S39-S42.

21. Wystrychowski G, Levin NW: Dry weight: sine qua non of adequate dialysis. Adv Chronic Kidney Dis 2007, 14(3):e10-e16.

22. Passauer J, Petrov H, Schleser A, Leicht J, Pucalka K: Evaluation of clinical dry weight assessment in haemodialysis patients using bioimpedance spectroscopy: a cross-sectional study. Nephrol Dial Transplant 2010, 25(2):545-551

23. Wabel P, Chamney P, Moissl U, Jirka T: Importance of whole-body bioimpedance spectroscopy for the management of fluid balance. Blood Purif 2009, 27(1):75-80

24. MoissI UM, Wabel P, Chamney PW, Bosaeus I, Levin NW, Bosy-Westphal A, Korth O, Müller MJ, Ellegård L, Malmros V, et al: Body fluid volume determination via body composition spectroscopy in health and disease. Physiol Meas 2006, 27(9):921-933.

25. Kotanko P, Levin NW, Zhu F: Current state of bioimpedance technologies in dialysis. Nephrol Dial Transplant 2008, 23(3):808-812.

26. Machek P, Jirka T, Moissl U, Chamney P, Wabel P: Guided optimization of fluid status in haemodialysis patients. Nephrol Dial Transplant 2010, 25(2):538-544.

27. Saran R, Bragg-Gresham JL, Rayner HC, Goodkin DA, Keen ML, Van Dijk PC, Kurokawa K, Piera L, Saito A, Fukuhara S, et al: Nonadherence in hemodialysis: associations with mortality, hospitalization, and practice patterns in the DOPPS. Kidney Int 2003, 64(1):254-262.

28. Hecking $M$, Antlanger $M$, Winnicki W, Reiter T, Werzowa J, Haidinger $M$ Weichhart T, Polaschegg HD, Josten P, Exner I, et al: Blood volume-monitored regulation of ultrafiltration in fluid-overloaded hemodialysis patients: study protocol for a randomized controlled trial. Trials 2012, 13:79.

29. Gabrielli D, Krystal B, Katzarski K, Youssef M, Hachache T, Lopot F, Lasseur C, Gunne T, Draganov B, Wojke R, et al: Improved intradialytic stability during haemodialysis with blood volume-controlled ultrafiltration. J Nephrol 2009, 22(2):232-240.

30. Damasiewicz MJ, Polkinghorne KR: Intra-dialytic hypotension and blood volume and blood temperature monitoring. Nephrology 2011, 16(1):13-18.

31. Charlson ME, Pompei P. Ales KL, Mackenzie CR: A new method of classifying prognostic comorbidity in longitudinal studies: development and validation. J Chronic Dis 1987, 40(5):373-383.

32. Kalantar-Zadeh K, Kopple JD, Kilpatrick RD, McAllister CJ, Shinaberger CS, Gjertson DW, Greenland S: Association of morbid obesity and weight change over time with cardiovascular survival in hemodialysis population. Am J Kidney Dis 2005, 46(3):489-500.

33. Kalantar-Zadeh K, Abbott KC, Salahudeen AK, Kilpatrick RD, Horwich TB: Survival advantages of obesity in dialysis patients. Am J Clin Nutr 2005, 81(3):543-554.

34. Kenchaiah S, Pocock SJ, Wang D, Finn PV, Zornoff LA, Skali H, Pfeffer MA, Yusuf S, Swedberg K, Michelson EL, et al: Body mass index and prognosis in patients with chronic heart failure: insights from the Candesartan in heart failure: assessment of reduction in mortality and morbidity (CHARM) program. Circulation 2007, 116(6):627-636.

35. O'Connor CM, Whellan DJ, Woidyla D, Leifer E, Clare RM, Ellis SJ, Fine L, Fleg JL, Zannad F, Keteyian SJ, et al: Factors related to morbidity and mortality in patients with chronic heart failure with systolic dysfunction the HF-ACTION predictive risk score model. Circ Heart Fail 2012, 5(1):63-71.

36. Caravaca F, Martínez Del Viejo C, Villa J, Martínez Gallardo R, Ferreira F: Hydration status assessment by multi-frequency bioimpedance in patients with advanced chronic kidney disease. Nefrologia 2011, 31(5):537-544

37. Tapolyai M, Faludi M, Réti V, Lengvárszky Z, Szarvas T, Berta K: Dialysis patients' fluid overload, antihypertensive medications, and obesity. ASAIO J 2011, 57(6):511-515.

38. Kalantar-Zadeh K, Kilpatrick RD, McAllister CJ, Greenland S, Kopple JD: Reverse epidemiology of hypertension and cardiovascular death in the 
hemodialysis population: the 58th annual fall conference and scientific sessions. Hypertension 2005, 45(4):811-817.

39. Colman S, Bross R, Benner D, Chow J, Braglia A, Arzaghi J, Dennis J, Martinez $L$, Baldo DB, Agarwal V, et al: The Nutritional and Inflammatory Evaluation in Dialysis patients (NIED) study: overview of the NIED study and the role of dietitians. J Ren Nutr 2005, 15(2):231-243.

40. Velasco N, Chamney P, Wabel P, Moissl U, Imtiaz T, Spalding E, McGregor M, Innes A, MacKay I, Patel R, et al: Optimal fluid control can normalize cardiovascular risk markers and limit left ventricular hypertrophy in thrice weekly dialysis patients. Hemodial Int 2012, 16(4):465-472.

41. Wabel P, Moiss U, Chamney P, Jirka T, Machek P, Ponce P, Taborsky P, Tetta C, Velasco N, Vlasak J, et al: Towards improved cardiovascular management: the necessity of combining blood pressure and fluid overload. Nephrol Dial Transplant 2008, 23(9):2965-2971.

42. Mominadam S, Ozkahya M, Kayikcioglu M, Toz H, Asci G, Duman S, Ergin P, Kirbiyik S, Ok E, Basci A: Interdialytic blood pressure obtained by ambulatory blood pressure measurement and left ventricular structure in hypertensive hemodialysis patients. Hemodial Int 2008, 12(3):322-327.

43. Costa E, Rocha S, Rocha-Pereira P, Castro E, Reis F, Teixeira F, Miranda V, Do Sameiro Faria M, Loureiro A, Quintanilha A, et al: Cross-talk between inflammation,coagulation/fibrinolysis and vascular access in hemodialysis patients. J Vasc Access 2008, 9(4):248-253.

44. Desai AS, Toto R, Jarolim P, Uno H, Eckardt KU, Kewalramani R, Levey AS, Lewis EF, McMurray JJ, Parving HH, et al: Association between cardiac biomarkers and the development of ESRD in patients with type 2 diabetes mellitus, anemia, and CKD. Am J Kidney Dis 2011, 58(5):717-728.

doi:10.1186/1471-2369-14-266

Cite this article as: Antlanger et al:: Fluid overload in hemodialysis patients: a cross-sectional study to determine its association with cardiac biomarkers and nutritional status. BMC Nephrology 2013 14:266.

\section{Submit your next manuscript to BioMed Central and take full advantage of:}

- Convenient online submission

- Thorough peer review

- No space constraints or color figure charges

- Immediate publication on acceptance

- Inclusion in PubMed, CAS, Scopus and Google Scholar

- Research which is freely available for redistribution 